\title{
Hipnose e dor: proposta de metodologia clínica e qualitativa de estudo ${ }^{1}$
}

\author{
Maurício da Silva Neubern² - Centro Universitário de Brasília, Brasília, Brasil
}

\begin{abstract}
Resumo
O presente trabalho visa apresentar uma proposta metodológica clínica e qualitativa para o estudo da relação entre hipnose e dor. Inicialmente, critica-se a pretensão de atribuir legitimidade científica exclusivamente para propostas estatísticas sobre o tema. Em seguida, são destacados alguns pressupostos da metodologia clínica e qualitativa, como a construção da realidade e das informações, as dimensões estética e técnica da relação terapêutica e a concepção da dor enquanto processo subjetivo. Uma vinheta clínica é utilizada de forma ilustrativa de modo a destacar as etapas e processos da pesquisa, como o uso dos registros e os processos interpretativos. Conclui-se o artigo ressaltando que a pertinência dessa metodologia se dá, basicamente, por abordar a dimensão subjetiva da relação entre dor e hipnose e por conceber o contexto como um conjunto de processos que não devem ser isolados, mas integrados à pesquisa.

Palavras-Chave: Metodologia qualitativa; psicologia clínica; hipnose; dor; subjetividade
\end{abstract}

\section{Hypnosis and pain: proposal of a clinical and qualitative research methodology}

\begin{abstract}
The purpose of this work is to present a proposal of clinical and qualitative methodology for the study of the relationship between hypnosis and pain. Initially, the pretension of attributing scientific legitimacy exclusively to statistical approaches on the theme is criticized. Then, some premises of the clinical and qualitative methodology are underlined, such as the construction of reality and information, esthetic and technical dimensions of therapeutic relationship and conception of pain as a subjective process. An illustrative clinical vignette is used so as to highlight the steps and processes of the research, such as the use of records and interpretative processes. The article is concluded emphasizing that the pertinence of this methodology is, basically, on its approach of relationship subjective dimension between pain and hypnosis and in its conceiving of the context as a set of processes that should not be isolated, but integrated into the research.

Keywords: qualitative methodology; clinical psychology; hypnosis; pain; subjectivity
\end{abstract}

\section{Introdução}

O estudo da hipnose no controle da dor tem trazido um problema considerável para a psicologia pela grande contradição subjacente à sua proposta desde os primeiros terapeutas da era moderna. Se, por um lado, sua eficiência é inquestionável, como pode ser notado desde os magnetizadores do século XIX, como Puységur, Cloquet e Esdaille (citados em Melchior, 1999), por outro, ainda existem problemas consideráveis que não foram resolvidos e permanecem um tanto incômodos nos planos epistemológico (Stengers, 2001). Nesse sentido, há o problema da complacência, segundo o qual não é possível ao pesquisador delimitar com precisão até que ponto as expressões do paciente hipnotizado constituem-se como dados legítimos, isto é, frutos de uma autêntica revelação da realidade, como reza a proposta moderna de ciência, ou se tais expressões são frutos de uma fabricação por parte do mesmo que, inconscientemente ou não, age de modo a atender suas próprias expectativas ou as do pesquisador (Chertok \& Stengers, 1989). Assim, de um ponto de vista metodológico inviabiliza-se a construção de um setting controlado e asséptico, em que as variáveis são devidamente conhecidas e controladas, onde é possível e, principalmente, desejável conceber e concretizar as caras noções modernas de predição e controle. Permanece sempre presente o fantasma da imprecisão, onde fato e artefato se misturam e se confundem, não oferecendo maiores perspectivas de certeza ao pesquisador.

Entretanto, o problema da complacência não impediu que determinados autores (Barber, 1996; Hilgard, 1967) afirmassem o advento de uma hipnose científica, baseada em métodos quantitativos ou experimentais. Para tais pesquisadores simples precauções metodológicas, como grupos de controle, controle de variáveis ou aplicação de escalas em ambientes pretensamente neutros, eliminam o problema e permitem a obtenção de dados confiáveis, de maneira que o setting hipnótico seja concebido como um legítimo contexto de descoberta de fatos, sem compreenderem a série de implicações de suas propostas. Assim, por meio de escalas de sugestionabilidade (Hilgard, 1967; Hilgard \& Hilgard, 1975), pretendeu-se responder a uma série de questões sobre a relação entre hipnose e dor, como

\footnotetext{
${ }^{1}$ O presente artigo é fruto da linha de pesquisa "Hipnose, subjetividade e dor: Construindo o Contexto Terapêutico" do Centro Universitário de Brasília. Ressalta-se aqui que este projeto foi aprovado pelo Comitê de Ética da instituição e está inscrito no Conselho Nacional de Ética em Pesquisa do Ministério da Saúde. Assim, foram devidamente tomadas as medidas de preservação da identidade do sujeito, como de sua integridade.

${ }^{2}$ Endereço para correspondência:

SEPN 707/907 - Campus do UniCeub - Faculdade de Ciências da Saúde e Educação - 70790 - 075 - Brasília-DF, Brasil.

E-mail: mneubern@hotmail.com
} 
até que ponto o sujeito é suscetível à hipnose, se ele pode ou não ser beneficiado com a intervenção hipnótica ou ainda até que ponto ele pode produzir um fenômeno anestésico. É como se as respostas produzidas num contexto controlado fossem consideradas válidas, já que não haveria qualquer influência indesejável em suas origens (Patterson \& Jensen, 2003; Spanos, 1986).

A princípio, tais propostas são problemáticas, pois arvoram-se a uma exclusividade científica, como se as demais formas de pesquisas não fossem merecedoras desse reconhecimento. Entretanto, enquanto se pretendem confiáveis, recusam-se ao questionamento sobre a complacência e suas consequências metodológicas que colocam em jogo a tão pretendida confiabilidade. Em termos gerais, é possível salientar que os procedimentos metodológicos estatísticos e experimentais distanciam-se do contexto relacional em que os processos hipnóticos emergem, para se centrar apenas nas respostas isoladas dos indivíduos. A resposta emitida numa determinada situação torna-se mais importante que o contexto, que os processos relacionais com os pesquisadores, que $o$ tipo de vínculo que desenvolvem, as possíveis expectativas dos sujeitos, suas emoções quanto a tal processo e, enfim, tudo o que possa constituir a subjetivação presente na hipnose. Em suma, para tais perspectivas, o contexto precisa ser controlado ou purificado ao invés de compreendido e assumido, já que não é concebido como condição para o acontecer do processo hipnótico em toda sua complexidade.

Há também outro tipo de limitação que, frequentemente, perpassa as metodologias estandardizadas, tais como as que procuram respaldar a cientificidade da hipnose. Nelas, as medidas e correlações apontam para uma generalização externa, uma entidade transcendente além dos sujeitos, cujos elementos que a integram obedecem a ordens de escores e escalas e não aos processos autor-regulados e históricos que constituem a subjetividade dos mesmos (Gonzalez Rey, 2005). Desse modo, os processos do sujeito não são relacionados à sua história, às construções de significados e sentidos, à sua emocionalidade e seu aprendizado, como também à subjetivação de processos socio-culturais em que toma parte. A dor, então, é vista como uma entidade independente, uma estrutura à parte que se torna acessível por meio de respostas externas quantificáveis.

Sendo assim, a proposta do presente artigo é a de apresentar uma metodologia clínica e qualitativa para o estudo da hipnose e suas relações com a dor. Trata-se de uma metodologia clínica que enfatiza a dimensão construtiva da interpretação (Gonzalez
Rey, 2000; 2005) em contraposição à de revelação ou descoberta e destaca a dor como um processo subjetivo (Erickson, 1980; Erickson \& Rossi, 1979). Para tanto, serão apresentados alguns de seus pressupostos a partir de uma vinheta clínica que visa mostrar sua aplicação numa situação concreta em que um sujeito feminino com diagnóstico de fibromialgia se submete a tratamento hipnótico. Vale ressaltar que o objetivo do trabalho não é o de discutir a natureza da hipnose, o que tem sido debatido largamente por alguns autores (Chertok, 1989; Melchior, 1998; Neubern, 2004; Stengers, 2001), mas apenas o de propor uma metodologia que possa abordar sua relação com a dor. Além disso, destaca-se que, por se tratar de um estudo clínico, será conferida certa ênfase no desenvolvimento do processo de mudança subjetiva do sujeito, principalmente no que se refere a sua experiência de dor, como da relação terapêutica entre o pesquisador e o sujeito.

\section{Proposta de metodológica qualitativa}

\section{Pressupostos}

\section{Construção da realidade}

$\mathrm{Na}$ perspectiva aqui adotada, concebe-se que a realidade não é revelada, mas construída com base as interpretações do pesquisador em suas relações com o sujeito pesquisado (Gonzalez Rey, 2000; 2005; Mahoney, 1991). A perspectiva da construção marca uma diferença fundamental com as perspectivas da revelação ou descoberta, para as quais existe uma separação entre sujeito e objeto, e as afirmações do pesquisador são representações dessa realidade externa (Demo, 2001). Na proposta aqui apresentada, a realidade emerge a partir de uma relação dialógica entre o pesquisador e o empírico, sendo construída por meio da integração de informações que surgem desse contato, tomando-se por base um marco teórico de referência. Portanto, a realidade (que compreende também a noção de objeto) é parte ativa do pensamento do pesquisador. Tal perspectiva é particularmente importante no que se refere ao problema da complacência por algumas razões. Primeiramente, as diversas formas de relação que se estabelecem no processo hipnótico não são tidas como uma interferência a ser evitada, mas como um momento constitutivo da prática hipnótica que necessita ser assumido e integrado à pesquisa. Assim, o pesquisador assume uma perspectiva reflexiva (Andersen, 1996; Keeney, 1997) que se volta para sua participação no processo e no contexto, suas formas de se relacionar com o sujeito, com a demanda de dor e com a própria hipnose. A construção do pensamento do pesquisador, portanto, não se faz pela restrição a 
algumas expressões externas do sujeito pesquisado, mas por uma compreensão mais ampla do contexto e da variedade de relações que aí tomam parte na construção do processo hipnótico e sua influência sobre a dor. Dessa complexidade presente no setting hipnótico provêm as informações que servirão para a construção das interpretações do pesquisador.

Outro aspecto importante refere-se ao problema da legitimação que, diferentemente das metodologias acima destacadas, não se valida por meio de critérios instrumentais e externos, como escalas e escores (Denzin \& Linconln, 1994; Turato, 2003). A legitimidade se consolida em função da coerência da interpretação do pesquisador, tanto com relação a seu marco teórico de referência, quanto ao empírico com o qual dialoga (Gonzalez Rey, 2000; 2005). A perspectiva de construção da realidade não implica a aceitação de qualquer interpretação do sujeito, uma vez que existem critérios para que as interpretações sejam legitimadas. Além disso, as construções do sujeito são sempre revistas em razão do papel ativo da realidade construída que pode perturbar e trazer novas questões ao pensamento do pesquisador. O objeto construído não é, portanto, passivo e dócil, pois também comporta elementos do empírico com o qual o pensamento do pesquisador dialoga e, por vezes, entra em conflito.

Suas interpretações não visam, portanto, uma correspondência direta e linear com o universo empírico, mas uma construção que permita oferecer diferentes possibilidades explicativas sobre o problema estudado, sem a exigência de um consenso entre pesquisadores distintos. Nesse sentido, serão adotados dois marcos teóricos de referência para as interpretações do pesquisador. O primeiro deles é a noção de subjetividade de Gonzalez Rey (2007), que consiste na constituição psíquica do sujeito que gera emoções, significados e sentidos a partir de sua ação em diferentes cenários sociais em que o mesmo toma parte. Tais construções, que compreendem emoções, significados e sentidos, integram-se em configurações, ou seja, uma unidade sistêmica que integra processos cognitivos e emocionais sem diluílos entre si. O segundo refere-se à noção de hipnose de Erickson (Erickson \& Rossi, 1980) que implica um estado de dissociação psíquica na qual os processos inconscientes tornam-se mais disponíveis, trazendo uma série de aprendizados e recursos que habitualmente se encontram além da intencionalidade do sujeito e podem ser utilizados para fins terapêuticos. Ela se diferencia das noções clássicas de hipnose por conceber que o fenômeno hipnótico nada mais é do que uma derivação das expressões cotidianas (comportamentos, processos mentais, aprendizados). Daí seu nome de hipnose naturalista, na qual o terapeuta busca desencadear e ampliar recursos que o sujeito já possui.

Construção das informações

$\mathrm{Na}$ proposta aqui apresentada, as informações não constituem processos à parte do pensamento do pesquisador, mas consistem nas primeiras aproximações deste com o empírico (Gonzalez Rey, 2005). Não cabe, portanto, a noção de coleta de dados, como se estes fossem representantes fidedignos de uma realidade externa, uma vez que as informações surgem a partir de uma postura ativa de construção desenvolvida pelo pesquisador ante seu campo de estudo. Daí a importância da noção de indicadores, unidades que integram diferentes informações oriundas do empírico e passam a ganhar sentido nas interpretações do pesquisador (Gonzalez Rey, 2000). Remetem a uma construção teórica na qual o que importa é a coerência da interpretação e não uma linearidade com as expressões do sujeito e seus processos. Sendo assim, o processo interpretativo não guarda uma relação linear com os registros de pesquisa, já que as informações são construções do pesquisador e não se esgotam em elementos descritivos de diários, filmagens e observações.

\section{Estética e técnica}

O processo de interpretação obedece aqui a duas dimensões distintas, mas intimamente articuladas: a estética e a técnica (Keeney, 1997). Por estética compreende-se um processo reflexivo sobre a dimensão relacional, em que o pesquisador, ao invés de focar as expressões do sujeito, volta suas construções sobre as formas de relação com o pesquisado, o vínculo que estabelecem e o próprio contexto da pesquisa. Já a técnica refere-se às construções sobre as expressões do sujeito, como sua autoimagem (Erickson citado em Haley, 1985), suas configurações subjetivas (Gonzalez Rey, 2007) sobre a dor e os próprios fenômenos hipnóticos desenvolvidos na relação com ele. Vale ressaltar que tais dimensões referem-se a um saber construído localmente sem a tentativa de identificar categorias de conteúdos ou padrões universais. Daí a importância que o estudo de caso ganha nesse tipo de pesquisa (Gonzalez Rey, 2000), principalmente tendo em busca compreender a singularidade dos processos construídos pelo sujeito em sua vivência de dor.

\section{Dor como processo subjetivo}

$\mathrm{Na}$ perspectiva aqui adotada concebe-se a dor como um processo subjetivo, uma vivência desenvolvida pelo sujeito em termos de significados, sentidos e emoções (Carvalho, 1997; Erickson, 1980; 
Gonzalez Rey, 2005). Isso não significa que se deva conceber que a dor seja necessariamente causada por tais processos, como se não houvesse uma causalidade orgânica, mas apenas que a dor ocorre num sujeito, não em um corpo inerte, e em determinados contextos socioculturais que lhe forjam elementos para a construção de sentido, ao invés de um lugar ideal e descontextualizado. Em outras palavras, mesmo uma dor de origem orgânica, como a de um tumor, implica a construção de uma série de significações, de processos emocionais, de aprendizados e afeta, de variadas formas, as redes sociais do paciente que podem acolhê-lo, envolvê-lo em conflitos, estigmatizálo, isolá-lo ou, ainda, participar ativamente em seu tratamento.

A relevância de tal concepção está no fato de que, sendo a dor uma experiência do sujeito, entrecruzada por processos históricos e pela dialética com o social, ela é passível de sofrer influência das relações em que o sujeito toma parte, o que pode propiciar uma abordagem terapêutica pertinente $\mathrm{e}$ eficaz para a mesma. Assim, a hipnose se torna particularmente útil em dois sentidos intimamente relacionados. Primeiramente, como recurso terapêutico, já que é concebida como um processo relacional e de influência mútua (Carvalho, 1997; Erickson \& Rossi, 1979) que pode assim reconfigurar a experiência dolorosa, promovendo novos arranjos de emoções, significados e sentidos. Em segundo lugar, por abrir espaço para a investigação do campo relacional e subjetivo que se configura no contexto de uma demanda ligada à dor, o que pode contribuir para uma compreensão mais abrangente da mesma em termos médicos e psicológicos.

\section{A pesquisa}

Conforme levantado, a vinheta clínica aqui apresentada servirá como uma ilustração da aplicação metodológica proposta, não comportando, assim, espaço para uma exposição mais detalhada sobre suas etapas e processos. A proposta é a de apontar para as possibilidades de aplicação de alguns momentos da interpretação que, num estudo de caso mais abrangente, ocorrem por meio de construções mais complexas.

\section{Os registros}

No caso específico da pesquisa aqui desenvolvida, houve os seguintes registros: filmagem; registros escritos da estagiária que atuou como observadora anotando literalmente as expressões verbais na sessão e registros do pesquisador sobre o caso, que já incluíam algum nível de interpretação. Periodicamente, tais registros eram discutidos reflexivamente (Andersen, 1996) pelo grupo de pesquisa, de modo a permitir o surgimento de indicadores sobre os processos estéticos e técnicos para, em seguida, propiciar a construção das interpretações parciais no diário de campo. Contudo, tais interpretações eram revistas e discutidas no grupo à medida que surgissem novos indicadores num processo dinâmico que assumiu a formação atual. Vale lembrar, por outro lado, que a construção de novas interpretações nem sempre se restringiu aos momentos estabelecidos pelo pesquisador, mas também pode surgir espontaneamente como insights em situações cotidianas (Neubern, 2003), o que também foi considerado neste processo.

\section{O sujeito}

Suzana, 46 anos, chegou até o pesquisador por intermédio de seu filho, que solicitou ajuda do mesmo após ouvir sua palestra sobre o tema. Ela aceitou trabalhar como sujeito voluntário desta pesquisa na qual o pesquisador era também $\mathrm{O}$ responsável pela condução do processo hipnótico. Suzana tinha três filhos (20, 22 e 24 anos), estava divorciada há oito anos e impossibilitada de trabalhar como costureira, sua profissão, há dois anos, em virtude de dores oriundas de uma fibromialgia, diagnosticada por seu médico. Este ainda lhe sugeriu que buscasse um psiquiatra para tratar de sua depressão, mas ela se recusou a tomar os remédios prescritos para tal problema. Logo que chegou para participar da pesquisa, além do tratamento médico, Suzana também se submetia a acupuntura, fisioterapia (com exercícios em piscina) e, posteriormente, quiropraxia. Ao todo ocorreram sete sessões semanais, sendo que apenas cinco contaram com induções hipnóticas. Posteriormente foram realizadas duas sessões de acompanhamento, com três e cinco semanas, respectivamente, após o término.

As interpretações

Seguindo-se os procedimentos já mencionados, as interpretações se desenvolveram em torno dos eixos técnicos e estéticos. Ocorreram focando alguns momentos das sessões, de maneira a destacar as correspondências entre a leitura feita pelo pesquisador em termos técnicos e estéticos, as intervenções desenvolvidas especificamente considerando as configurações do sujeito e as mudanças ocorridas posteriormente às intervenções. Considera-se que tais correspondências são de grande importância para destacar as relações entre a intervenção hipnótica e as mudanças na experiência dolorosa ${ }^{3}$.

\footnotetext{
${ }^{3}$ As expressões em itálico, quando entre aspas, referem-se a expressões literais do sujeito. Sem aspas, são indicadores construídos pelo pesquisador a partir das informações que emergiram no contexto clínico.
} 
Foco estético - Logo de início, Suzana se queixou de que em todos os tratamentos que tinha percorrido, os profissionais "não haviam dado as devidas atenções a seu problema". Ela relatava se sentir "desprezada por eles" que, para ela, estavam com outros interesses, como não perder tempo com pacientes de convênio ou não dar atenção a seus problemas emocionais. Suzana se sentia numa situação difícil e os profissionais não the prestavam o apoio que ela julgava necessário. Além disso, as prescrições dos mesmos não resultavam em quaisquer benefícios quanto a suas dores. Daí sua rebeldia em tomar o remédio psiquiátrico, se o profissional nem sequer havia parado para lhe escutar. Interpretação - Isso permite considerar que Suzana possuía um grande desejo de ser acolhida e compreendida por algum profissional, mas até o momento havia passado por muitas frustrações nos contextos relacionais em que tomava parte.

Logo que seu filho lhe falou sobre a pesquisa, ela afirmou: "Se ele vai fazer uma pesquisa, então o negócio é sério." Assim, desde o início, ela se dirigia ao pesquisado como professor ou doutor e afirmava estar disponivel para colaborar no que fosse necessário para a pesquisa. O pesquisador, por sua vez, oferecen acolbimento para escutá-la e ponderar com ela sobre os problemas que a acometiam, assim como suas implicações. Interpretação - Desse modo, Suzana apresentava uma considerável disposição para colaborar com o trabalho, já que entendia que ali seria possível atender a suas necessidades de acolhimento além da esperança de um procedimento efetivo quanto a suas dores.

Porém, esse processo ficou mais claro a partir da terceira sessão, quando ela resolveu lhe contar várias histórias tristes de sua vida, acentuando que "o doutor não sabe da missa a metade" e "precisa saber para me entender melhor". Vez por outra, ela questionava se aquilo não atrapalharia a pesquisa, mas continuou a relatar mais ainda suas histórias quando o pesquisador the disse que aquilo ajudaria o trabalho. Interpretação - Assim, é possível considerar que esses momentos iniciais permitiram a construção de uma relação colaborativa e formação inicial de um vínculo, na qual o sujeito se sentia reconhecido em seu sofrimento (e não mais alguém a ser desprezado) e enxergava a possibilidade de se submeter a um tratamento sério (efetivo), enquanto o pesquisador ocupava a posição de alguém interessado em acolhê-la e ajudá-la.

Foco técnico - Logo que veio para o trabalho, Suzana, apresentava uma postura recurvada e um semblante que parecia expressar dores. Segundo os relatos de Suzana sobre o que seu médico lhe disse, suas dores eram diversas. Havia um foco de dor na região superior das costas por causa de uma calosidade resultante de um acidente de carro (em que sua coluna teria feito o movimento de chicote). Outro era atribuído à fibromialgia, que começava na nuca e descia pelos braços até os pulsos. Vez por outra, também apareciam nas pernas e havia ainda uma dor aguda na mão esquerda (uma tendinite entre o polegar e o pulso) devido a movimentos repetitivos. Apesar de um sorriso no rosto, suas expressões geralmente pendiam para acentuado negativismo: ela "me sinto parada no tempo" e "não vejo chances futuras de sair dessa paralisia". Tal situação era compreensível por várias razões, a começar pelo fato de que as dores a impediam de exercer sua profissão. Suzana sempre fora "orgulhosa por ter conseguido exercer uma profissão e, mesmo divorciada, criar os três filhos, que já estavam na faculdade". Além disso, sua profissão a fazia alguém importante socialmente, pois além de propiciar emprego a outras pessoas, era muito requisitada pelas clientes, tanto pela qualidade de seu trabalho, como para conselhos sentimentais. Interpretação Tais indicadores apontam para uma configuração de grande sofrimento do sujeito, pois não conseguia mais exercer seu papel de provedora junto a seus filhos (sempre muito importantes para ela), que agora se organizavam para cuidar da mãe; ela vivia a dolorosa posição de uma inversão de papel causada pelas dores. Além disso, tais dores a levavam a viver uma espécie de morte social, pois saía de uma posição central, de grande importância para muitas pessoas, para se restringir à sua casa, onde não fazia praticamente qualquer atividade, ou aos tratamentos, onde era uma doente desprezada.

Chama-se também a atenção para o fato de que Suzana, no relato da terceira sessão, quis contar sua história, dando ênfase a uma série de acontecimentos afetivos trágicos: as bumilhaçooes que sofreu de seu marido durante o casamento; as humilhações que sofreu por parte deste e de sua amante; o fato de ter presenciado o suicídio de um ex-namorado logo após sen casamento; e não ter encontrado mais ninguém que amasse de verdade; as dificuldades crescentes em sustentar os filhos; o surgimento das dores e a impossibilidade de trabalhar, dentre outros. Em meio a tal narrativa, o pesquisador perguntou se isso lhe passava alguma mensagem, ao que ela respondeu: "Acho que não posso ser feliz”. Interpretação - Tais indicadores apontam para configurações de uma autoimagem bastante negativa, pois remetem a alguém que fracassa no amor, no trabalho e no sustento da família, e que parece viver um mandato de que a felicidade é algo que não está a seu alcance. Toda essa noção ampla de fracasso, como mãe, mulher e profissional, com toda uma forma de se situar em sua história como alguém que é sempre vítima da vida permite 
conceber processos de intensa desqualificação de si mesma e intensa autoagressão.

Intervençôes hipnóticas - Tendo desenvolvido tal compreensão sobre o sujeito, cabia ao pesquisador, então, desenvolver uma série de intervenções voltadas para a singularidade de Suzana, quanto a suas construções de sentido e necessidades. Cada intervenção deveria visar determinados objetivos e desencadear certos processos de mudança específicos, conforme será ilustrado a seguir.

Rapport - Ao preparar uma intervenção para Suzana, o pesquisador comecou pontuando que ela havia lhe contado uma história com muitas situaçoes tristes e dolorosas. Ao mesmo tempo, era difícil entender como ela, em meio a tantas mensagens de infelicidade, conseguiu tantas vitórias, como tirar a carteira de motorista, desenvolver uma profissão e ser bem sucedida com ela, suportar todas as dificuldades e criar seus filhos e educa-los como homens de bem. Então, ele the disse que agora era a vez. dele contar-lhe algumas histórias e que, em transe, ela poderia apreciá-las com mais profundidade. Interpretação - Com isso o terapeuta se utiliza de uma forma de linguagem tipicamente hipnótica - o rapport - na qual ele legitima e acolhe sua história (como quando se refere a seu sofrimento) e, ao mesmo tempo, desvia seu foco de atenção para processos que estão marginais quanto a suas construções negativas dominantes, mas que podem servir de possibilidades para novas construções, principalmente porque são acontecimentos de sua própria experiência.

Acompanhamentos corporais - "E, enquanto ex converso com você, a sua respiração flui e você pode perceber o contato de seu corpo com a poltrona ... o contato de sua pele com o tecido de sua roupa ... o ar entrando pelas suas narinas ... e, em transe, as pessoas podem perceber muitas coisas interessantes que habitualmente não percebem ... a sensação dos músculos relaxando, a sensação do ar tocando a pele, ... a sensação do que ocorre por dentro da pele. Porque quando nosso pensamento vai tocando as partes do corpo percebemos alguma diferença nessas partes. E eu fico imaginando como seu pensamento toca a região de sua nuca, de seus ombros, de suas costas." ... "e sua respiração sabe o que fazer... e sua circulação sabe o que fazer, e seu corpo sabe o que fazer ... porque seu pensamento desce pelas suas costas e ele pode ir para outro lugar, como suas pernas ... e ali você não precisa fazer nada, porque seu corpo sabe deixar as coisas fluirem, $e$ sua perna sabe deixar as sensaçôes fluirem e escorrerem para o chão." Interpretação - Essa forma de intervenção consiste em uma linguagem que se volta sobre os processos corporais. Além de ser algo condizente com a sinestesia desse sujeito (o que foi verificado logo no início das sessões) é também um processo útil para produzir fenômenos de redução da dor por meio de anestesias e analgesias. Essa forma de linguagem apresenta muitas particularidades úteis para Suzana, a começar pelo fato de fazer referências constantes a percepções que as pessoas não possuem habitualmente de processos psicofisiológicos que ocorrem cotidianamente. Assim, fica a sugestão de que muitos processos ocorrem além da percepção consciente e que os mesmos podem ser utilizados a seu favor dentro da idéia de que tais processos possuem uma sabedoria e sabem o que fazer se o sujeito os deixa fluir. Essa forma de linguagem é útil ainda por se tratar de uma pessoa que possui referências limitadas e incapacitantes sobre sua situação em razão de uma série de construções negativas. Além disso, a intervenção também sugere que, nesse estado de conforto, toda vez que seu pensamento incidir sobre alguma parte do corpo, ela começará a sentir algo diferente, termo geral que pode oferecer várias possibilidades de adjetivo para o sujeito. Nesse contexto terapêutico, como ela vive um processo de dor, poderá associar a alguma percepção contrária à mesma. Por fim, tal sugestão visa aproveitar uma sequência de deslocamentos trazidos por Suzana: ela mesma afirmava que suas dores começavam em cima (nuca) desciam pelo corpo e, quando chegavam às pernas, escorriam para o chão. As sugestões nesse sentido nada mais fizeram do que aproveitar e acelerar esse mecanismo cotidiano.

Distorção do tempo - "E você me contou uma história muito rica, com muitos detalhes. E você se acostumou a contar essa história desse jeito. E existem muitos detalhes que sen consciente não captou, mas que seu inconsciente sabe. Porque nosso consciente capta apenas uma pequena parcela de nossa experiência. Enquanto conversamos, seu inconsciente pode se preparar para algo muito importante que vou lhe dizer daqui a alguns segundos"... "E a coisa importante que tenho para dizer a ele é que ele pode rever sua bistória inteira em poucos segundos, como se fosse num filme ... e ele pode fazer isso uma vez, duas vezes, cinco, dez vezes, ... e ele pode fazer isso quantas vezes forem necessárias para enxergar mais detalhes nessa história." "parada no tempo". Interpretação - A distorção do tempo foi aplicada aqui por algumas razões. A primeira delas refere-se à possibilidade de trazer algum movimento à sua dimensão temporal, já que ela mesma havia afirmado estar "parada no tempo". Assim, o fenômeno de distorcer o tempo no contar da história implicava a possibilidade de sair dessa paralisia, de poder lidar com o tempo de uma forma mais flexível e livre. Em segundo lugar, o fenômeno da distorção também foi induzido buscando introduzir a possibilidade de captar vários detalhes de sua história de que ela não se lembrava ou não aoa quais atribuía algum valor. Como Suzana estava muito presa numa sequência negativa de 
eventos, essa técnica foi importante para passar a sugestão de que existem outros eventos além destes que podem ser de grande valia para mudar os sentidos mais amplos configurados em sua narrativa sobre si mesma.

Metáfora - "E é muito curioso quando a criança está aprendendo a andar. Suas pernas ainda não têm força para sustentar seu corpo e ela acaba caindo. Usa os braços, apoia-se em objetos, na parede,... mas acaba caindo. Mas ela continua tentando e vai acumulando muitas coisas em si, sem saber que acumula esses processos em si ... e um dia, ela consegue ficar em pé e cai novamente ... e ela continua a tentar, ficar de pé e cair ... e chega a cair 3.000 vezes, mas isso não a impede de tentar ... até o dia em que pode andar $e$ raramente cair." A metáfora hipnótica é contada com termos gerais que permitam ao sujeito criar associações de acordo com suas necessidades (Erickson \& Rossi, 1979). Para alguém que vivia uma espécie de morte social, como Suzana, a metáfora de uma criança aprendendo a andar é significativa, pois sugere um recomeço que está sujeito a quedas, mas também a processos intensos de aprendizagem que são recompensados com várias pequenas vitórias ao longo desta etapa.

Indicadores de mudança - A partir dessas intervenções, Suzana apresentou mudanças bastante significativas, a começar pelo prolongamento acentuado do tempo de alivio. Tais modificações possuem, segundo as teorias hipnóticas (Erickson \& Rossi, 1980), estreita relação com os fenômenos de sugestão póshipnótica que procuram reproduzir fora do espaço da sessão, as mesmas sensações e experiências da sessão. No caso de Suzana, sugeriu-se que com o passar dos dias seu corpo e sua mente aprenderiam a prolongar gradativamente sua sensação de alívio por alguns minutos. Relatou que este durou cinco dias, que após um conflito em casa com os filhos a dor retornou, mas que com a ajuda de um quiroprata, conseguiu retomar o alívio. Sem dúvida, o auxílio desse profissional foi de grande importância para o sujeito. Porém, pelos outros indicadores presentes, é possível considerar que as mudanças ocorridas em termos configuracionais e emocionais também foram decisivas para o alívio da dor.

Nesse sentido, as mudanças foram gradativas: sua fisionomia apresentava-se mais leve, destituida de expressões de dor e tristeza; seu semblante apresentava mudanças visiveis quanto à sessão anterior e também apresentava-se mais produzida em termos de roupas $e$ bijuterias; suas falas referiam-se a situaçôes cotidianas e não apenas à dor e às frustrações com o tratamento; trazia a idéia de retomar algum tipo de trabalho e pediria ajuda a seu médico sobre o que seria possivel fazer; passava a se referir de forma positiva aos outros profissionais; e relatava que a dor havia redurido 90\%. Mas talvez o mais interessante tenha sido o fato de que, antes da última sessão de acompanhamento (follow-up), Suzana relatou ter passado por uma experiência muito sofrida, na qual um primo próximo havia falecido repentinamente. Então, ela sentiu que, ante tal crise, as dores estavam retornando, o que a levou a pensar: "Não posso voltar para aquele estado" (referindo-se a seu emocional), o que a fez. tentar repetir sozinha em casa os exercícios de hipnose. Ela acrescentou que teve a preocupação de não deprimir, pois, caso isso ocorresse, as dores voltariam a se intensificar. Interpretação - Tais indicadores trazem reflexões bastante significativas em relação às mudanças ocorridas. Primeiramente, referem-se a um processo de construção no qual as expressões revelam uma mudança qualitativa em sua forma de narrar sua vida cotidiana, o que foge de uma intenção puramente deliberada de confirmar o terapeuta. Suas falas voltam-se, portanto, para situações cotidianas e não apenas para a dor, que deixa de ser seu único foco. Em segundo lugar, há uma série de pequenas modificações que denunciam reconfigurações significativas quanto à imagem de si mesma e de sua dor. Suzana não se colocava mais como uma vítima de sua história, mas como uma pessoa que possui várias outras formas de subjetivação, que mostra interesse estético quanto a sua própria aparência e passa a buscar outras possibilidades de futuro quanto a emprego e inserção social. A dor, sendo reduzida, passa de algo incontrolável e inatingível para algo que pode ser influenciado. Em terceiro lugar, o espaço de tratamentos também adquire novas construções de sentido, indo de espaços ineficazes e pouco acolhedores para espaços onde ocorriam mudanças e o vínculo se tornava possível, o que atendia sobremaneira a uma de suas necessidades principais a de ser devidamente acolhida. E, finalmente, outro indicador significativo refere-se a sua possibilidade de poder identificar os processos ligados à dor (no caso sua mudança emocional) e poder assumir uma postura ativa em relação a eles de maneira a evitar que se instalassem novamente.

\section{Discussão e considerações finais}

A pertinência de uma metodologia clínica e qualitativa para estudos sobre a relação entre hipnose e dor pode ser considerada a partir de dois pontos básicos, profundamente relacionados. Primeiramente, por conceber a dor como um processo subjetivo, situando-a no cenário subjetivo de um sujeito singular e não como a expressão de um corpo anônimo, descontextualizado e sem história. No caso específico aqui apresentado, percebeu-se que a dor de 
Suzana estava integrada a configurações de suas dificuldades em prover a família, ao histórico de sofrimento afetivo, à autoimagem negativa, à perda de sua profissão e ao isolamento social a que esta a levou. Nesse sentido, observou-se que a reconfiguração desses processos coincidiu com o alívio considerável da dor que já a acometia há alguns anos. Tal perspectiva abre um campo amplo de reflexões sobre a dor, para o qual as metodologias estatísticas e experimentais não possuem sensibilidade por não possuírem instrumentos $\mathrm{e}$ conceitos que compreendam a singularidade do sujeito e seus enraizamentos subjetivos, históricos e socioculturais (Gonzalez Rey, 2007). Observa-se que o tipo de construção, perguntas e investigação acompanhou um delineamento radicalmente distinto no caso aqui discutido em comparação com os estudos clássicos (Hilgard, 1967) ou mesmo mais recentes (Nogueira, Lauretti \& Costa, 2005). A título de breve ilustração nesse sentido, no caso de Suzana, o acolhimento prestado ao sujeito e a individualização do tratamento hipnótico obedeciam a necessidades do processo e se constituíam, portanto, como condições de legitimação da pesquisa.

Este ponto traz ainda uma reflexão particular quanto à hipnose na relação com a dor no que se refere ao problema da causalidade. Isso porque, tal como exemplificam Nogueira, Lauretti e Costa (2005), existe na literatura médica a idéia de que determinadas expressões dolorosas, como as da fibromialgia, em determinados grupos de sujeitos não possuem relação com o psicológico ou o cognitivo. Compreende-se que tal afirmação pode ser pertinente no que se refere a uma causalidade direta e linear, mas não quanto a influência, como destacado por tal literatura, como se dor e subjetividade fossem processos inteiramente distintos. A hipnose revestese de importância nesse ponto, pois mesmo em situações de causalidade orgânica constatada, como tumores cancerígenos, queimaduras ou anestesias cirúrgicas, ela pode ser relativamente bem sucedida, exatamente por trabalhar nas dimensões subjetivas do processo doloroso (Erickson, 1980). Dito de outro modo, a hipnose permite que se considere inapropriado conceber a dor como processo isolado da subjetividade, mesmo quando seja possível constatar uma causa orgânica para o processo.

Em segundo lugar, a pertinência da metodologia apresentada também se dá em virtude da consideração do contexto como um conjunto de processos constituintes da pesquisa. No caso aqui discutido, pôde-se perceber como toda uma rede relacional de frustrações estava ligada à subjetivação da dor e como isso se configurava junto ao sujeito na forma de negativismo quanto aos tratamentos $\mathrm{e}$ pouca expectativa de melhora da dor. Também foi possível constatar como a dimensão estética de acolhimento e de uma proposta concreta do pesquisador (hipnose) pôde desfazer alguns desses processos e desencadear mudanças significativas, como o alívio da dor e as relações com outros profissionais. Isso permite a constatação de que a subjetividade, a dor e a hipnose são processos que remetem a uma dialética entre sujeito e contexto e que, por tal razão, as metodologias experimentais e estatísticas desconsideram importantes momentos da constituição dos mesmos. A subjetividade, como a dor, organiza-se em redes sociais de construção de sentido (Andersen, 1996) que perpassam os diferentes momentos do sujeito em sua vida cotidiana, enquanto a hipnose não se restringe a uma aplicação técnica unilateral, pois consiste em um processo relacional de múltiplos níveis de influência mútua que é perpassado pelo contexto em que ocorre (Erickson, 1980).

Enfim, o que se pretendeu destacar neste trabalho foi a legitimação da proposta clínica e qualitativa que, apesar de sua pertinência, tem sido desconsiderada por autores que apontam para uma única opção de reconhecimento científico (Denzin \& Lincoln, 1994; Gonzalez Rey, 2005; Turato, 2003). Não se buscou, como objetivo, negar legitimidade aos métodos quantitativos e experimentais, mas apenas destacar algumas de suas limitações e questionar a pretensa superioridade destacada por alguns autores já citados. Em suma, os métodos qualitativos abrangem momentos do real que são de grande relevância para o estudo entre hipnose e dor, que merecem mais aprofundamentos de pesquisa, uma vez que tais processos têm se mostrado de considerável importância para tal estudo, seja em relação sua pertinência científica, seja em quanto à de sua importância para o alívio da dor.

\section{Referências}

Andersen, T. (1996). Processos reflexivos. (R. M. Bergallo, Trad.). Rio de Janeiro: Noos. (Publicação original 1991).

Barber, J. (1996). Hypnosis and suggestion in the treatment of pain. New York: Norton.

Carvalho, M. (1997). A hipnoterapia no tratamento da dor. Em M. Carvalho (Org.). Dor: um estudo multidisciplinary (pp. 222-247). São Paulo: Summus. 
Chertok, L. (1998). Le non savoir des psys. Paris: Synthélabo.

Chertok, L. \& Stengers, I. (1989). Le coeur et la raison. L'bypnose en question de Lavoisier à Lacan. Paris: Payot.

Demo, P. (2001). Pesquisa e informação qualitativa. Campinas: Papirus.

Denzin, N. \& Lincoln, Y. (1994). Handbook of qualitative research. Londres: Sage.

Erickson, M. (1980). An introduction to the study and application of hypnosis for pain control. Em M. Erickson \& E. Rossi (Org.). The collected papers of Milton Erickson, MD vol IV - (pp. 237-245). New York: Irvington.

Erickson, M. \& Rossi, E. (1979). Hypnotherapy: an exploratory casebook. New York: Irvington.

Erickson, M. \& Rossi, E. (1980). The collected papers of Milton H. Erickson, MD. New York: Irvington.

Gonzalez Rey, F. (2005). Pesquisa qualitativa $e$ subjetividade. São Paulo: Thomson.

Gonzalez Rey, F. (2000). Pesquisa qualitativa: caminhos e desafios. São Paulo: Thomson.

Gonzalez Rey, F. (2007). Psicoterapia e subjetividade na pós-modernidade. São Paulo: Thomsom.

Haley, J. (1985). Conversations with Milton Erickson, MD. Changing individuals. New York: Triangle Press.

Hilgard, E. (1967). A quantitative study of pain and its reduction through hypnotic suggestion. Proceedings of the National Academy of Science, 57, 1581-1586.

Hilgard, E. \& Hilgard, J. (1975). Hypnosis in the relief of pain. New York: Brunner/Mazel.
Keeney, B. (1997). A estética da mudança. (M. Lopes \& M. Carbajal, Trad.). Campinas: Psy II. (Publicação original, 1983).

Mahoney, M. (1991). Human change process. New York: Basic Books

Melchior, T. (1998). Créer le reel. Paris: Seuil.

Neubern, M. (2004). Histórias que (não) curam: sobre narrativas em hipnose clínica. Psicologia: Ciência e Profissão, 3, 58-65.

Nogueira, C., Lauretti, G. \& Costa, R. (2005). Avaliação duplamente encoberta da hipnose em fibromialgia. São Paulo Medical Journal, 123 (suppl), 14-14.

Patterson, D. \& Jansen, M. (2003). Hypnosis and clinical pain. Psychological Bulletin, 129(4), 495-521.

Rossi, E. \& Cheek, D. (1988). Mind-body therapy. Methods of ideodynamic healing in hypnosis. New York: Norton.

Spanos, N. (1986). Hypnotic behavior: a socialpsychological interpretation of amnesia, analgesia and "trance logic". The behavioral and brain sciences, 9, 449-502.

Stengers, I. (2001). Qu'est-ce que l'hypnose nous oblige à penser? Ethnopsy. Les Monde Contemporain de la Guerison, 3, 13-68.

Turato, E. (2003). Tratado da metodologia da pesquisa clínico-qualitativa. Petrópolis: Vozes.

Recebido em outubro de 2007

Reformulado em novembro de 2008

Aprovado em fevereiro de 2009

Sobre o autor:

Maurício da Silva Neubern é doutor em Psicologia pela Universidade de Brasília (UnB), psicólogo clínico e psicoterapeuta. Fundador do Instituto Milton H. Erickson de Brasília, também atua como formador de terapeutas. Atualmente é professor no Centro Universitário de Brasília, onde leciona disciplinas relacionadas à psicologia clínica. 